\title{
Iron Therapy in Pregnant Women
}

\author{
Iosief Abraha*
}

\section{Mauro Marchesi Immunotransfusion Service, Perugia Hospital Com COMMENTARY}

Pregnancy is characterized by a remarkable maternal physiological change with an intense fetal growth that needs adequate nutrition. Epidemiological evidence suggest that between $11 \%$ and $45 \%$ of women in Western countries of childbearing age have depleted iron stores [1] and this explains why most pregnant women are found with totally depleted iron stores. Limited iron stores may lead to iron deficiency that is the most leading cause of anemia in pregnancy [2]. The prevalence of iron deficiency in pregnancy depends much on the economic status of the population and it varies from $20 \%$ to $90 \%$ [3].

Observational studies suggest that iron deficiency without anemia has important implications to the child and mother health. For example, some report a strong correlation between low maternal serum ferritin concentrations and iron deficiency anemia in neonates [4,5] which may lead to consequence on motor, social-emotional, and neurophysiologic development [6] as well as a long lasting implication on cognitive and behavioral abnormalities [7]. Iron deficiency anemia is reported to lead to several adverse consequences the mother and child health described in the medical literature. These include increased rates for cesarean delivery, premature birth, low infant birth weight perinatal bleeding, preeclampsia, placental abruption, poor maternal thyroid status, cardiac failure, and mortality as well as poor wound healing and increased demand of transfusion [6, 8-11]. Despite the quality of the evidence concerning these negative consequences has not been completely addressed and some adverse effects has not been confirmed in other studies [12], screening for maternal iron deficiency should be mandatory.

Screening can be performed by readily available inexpensive tests that include serum ferritin, total iron binding capacity, and percent transferrin saturation (TSAT). Total iron binding capacity and TSAT are required because serum ferritin can falsely be increased during morbidities such as autoimmune diseases. Iron deficiency is considered present when TSAT $<20 \%$ and/or ferritins $<30 \mathrm{ng} / \mathrm{mL}$.

There is a preponderance of published studies in the medical literature addressing the efficacy of iron therapies to treat or prevent outcomes in pregnancy. A recent systematic overview of reviews identified 11 studies that encompassed 31 randomized trials with over 40000 participants and an impressive number of outcomes [13]. A multidisciplinary panel was able to prioritize critical maternal and neonatal outcomes using the Delphi method. Critical maternal outcomes resulted in incidence of anemia (defined as $\mathrm{Hb}<11 \mathrm{gr} / \mathrm{dl}$ ) and iron deficiency anemia. Pooled data from 14 studies with 3831 participants showed that iron based interventions may reduce the incidence of anemia by $62 \%$ (RR 0.38 (95\% CI 0.26 to 0.53 ) with a number needed-totreat (NNT) of 4 . This evidence was however judged low according to the GRADE method [14] due to important heterogeneity and serious concerns in terms of risk of bias. Heterogeneity could be attributed to several factors including differences in doses of the interventions (iron therapies varied from $30 \mathrm{mg}$ to $1000 \mathrm{mg}$ per day), Hb level at study entry (ranging between $\geq 10 \mathrm{gr} / \mathrm{dl}$ and $\geq 13.2 \mathrm{gr} / \mathrm{dl}$ ), other inclusion criteria of the population as well as setting (the trials were performed in several different countries across the globe). Investigation of the heterogeneity did not provide any solution, however, subgroup analysis limited to the studies with low risk of bias confirmed that iron based therapies can reduce the risk of anemia by $59 \%$ (RR 0.41 (95\% CI 0.23 to 0.73)) with an unchanged NNT. The level of evidence was thus judged moderate which means that it is likely that further evidence can change the confidence in the treatment effect.

Analysis regarding iron deficiency anemia, the second maternal outcome, confirmed that iron reduced iron deficiency anemia by 67\% (RR 0.33, 95\% CI 0.16 to 0.69) albeit low level evidence (due to very serious concern in terms of risk of bias). However, no evidence of difference was observed in terms of preterm birth, neonatal death and low birth weight with a low quality of evidence despite adequate number of participants (at least 15,000 for each outcome). Of note is the absence of heterogeneity when pooling the results of these outcomes, and this suggests that these outcomes are not so critical in the setting of iron deficiency.

In addition, it must be emphasized that there is lack of published studies that compare oral therapies against specific diet with good iron availability in pregnant women. Guideline *Correspondence to: Iosief Abraha, Mauro Marchesi Immunotransfusion Service, Perugia Hospital Company, Perugia, Italy, E-mail:
iosief_a@yahoo.it

Received: July 16, 2019; Accepted: July 22, 2019; Published: July 29, 2019

Citation: Abraha I (2019) Iron Therapy in Pregnant Women. Clinics Mother Child Health. 16:326.

Copyright: (C) 2019 Abraha I. This is an open-access article distributed under the terms of the Creative Commons Attribution License, which permits unrestricted use, distribution, and reproduction in any medium, provided the original author and source are credited. 
developers recommend to assess women's nutritional status before and at the start of pregnancy as both under nutrition and over nutrition can be associated with adverse pregnancy outcomes [15]. With the reviewed moderate evidence reported above, there is a good ground to formulate strong recommendation in favor of oral iron therapy to prevent iron deficiency anemia, but we think that it should be provided after optimized maternal nutrition approach has been insufficient.

\section{REFERENCES}

1. Hallberg L. Results of surveys to assess iron status in Europe. Nutrition Reviews. 1995;53:314-22.

2. Scholl TO. Maternal iron status: Relation to fetal growth, length of gestation, and iron endowment of the neonate. Nutrition Reviews. 2011;69:23-29.

3. Auerbach M, Abernathy J, Juul S, Short V, Derman R. Prevalence of iron deficiency in first trimester, nonanemic pregnant women. J Matern Fetal Neonatal Med. 2019:1-4.

4. Shao J, Lou J, Rao R, Georgieff MK, Kaciroti N, Felt BT, et al Maternal serum ferritin concentration is positively associated with newborn iron stores in women with low ferritin status in late pregnancy. The Journal of Nutrition. 2012;142:2004-9.

5. Akhter S, Momen MA, Rahman MM, Parveen T, Karim RK. Effect of maternal anemia on fetal outcome. Mymensingh Medical Journal: MMJ. 2010;19:391-8.

6. Drukker L, Hants Y, Farkash R, Ruchlemer R, Samueloff A, Grisaru-Granovsky S, et al. Iron deficiency anemia at admission for labor and delivery is associated with an increased risk for Cesarean section and adverse maternal and neonatal outcomes. Transfusion. 2015;55:2799-806.

7. Congdon EL, Westerlund A, Algarin CR, Peirano PD, Gregas M, Lozoff B, et al. Iron deficiency in infancy is associated with altered neural correlates of recognition memory at 10 years. The Journal of Pediatrics. 2012;160:1027-33.
8. Juul SE, Derman RJ, Auerbach M. Perinatal Iron Deficiency: Implications for mothers and infants. Neonatology. 2019;115:269-74.

9. Daru J, Zamora J, Fernandez-Felix BM, Vogel J, Oladapo OT, Morisaki N, et al. Risk of maternal mortality in women with severe anaemia during pregnancy and post-partum: A multilevel analysis. The Lancet Global Health. 2018;6(5): 548-54.

10. Ronnenberg AG, Wood RJ, Wang X, Xing H, Chen C, Chen D, et al. Preconception hemoglobin and ferritin concentrations are associated with pregnancy outcome in a prospective cohort of Chinese women. The Journal of Nutrition. 2004;134:2586-91.

11. Scanlon KS, Yip R, Schieve LA, Cogswell ME. High and low hemoglobin levels during pregnancy: differential risks for preterm birth and small for gestational age. Obstetrics and Gynecology. 2000;96:741-48.

12. Cantor AG, Bougatsos C, Dana T, Blazina I, McDonagh M. Routine iron supplementation and screening for iron deficiency anemia in pregnancy: a systematic review for the U.S. Preventive Services Task Force. Annals of Internal Medicine. 2015;162:566-76.

13. Abraha I, Bonacini MI, Montedori A, Di Renzo GC, Angelozzi P, Micheli $\mathrm{M}$, et al. Oral iron-based interventions for prevention of critical outcomes in pregnancy and postnatal care: An overview and update of systematic reviews. Journal of Evidence-Based Medicine. 2019;12:155-66.

14. Atkins D, Best D, Briss PA, Eccles M, Falck-Ytter Y, Flottorp S, et al. Grading quality of evidence and strength of recommendations. Bmj. 2004;328:1490.

15. Hanson MA, Bardsley A, De-Regil LM, Moore SE, Oken E, Poston $\mathrm{L}$, et al. The international federation of gynecology and obstetrics (FIGO) recommendations on adolescent, preconception, and maternal nutrition: Think nutrition first. Int J Gynecol Obstet 2015;131:213-53. 